\title{
Educação Ambiental: um estudo de caso em uma comunidade ribeirinha do Estado do Amazonas
}

\author{
Maria de Nazaré Leal Nogueira ${ }^{1}$ \\ Leandro de Oliveira Souza ${ }^{2}$
}

\begin{abstract}
RESUMO
O presente artigo é resultado de uma investigação que objetivou entender o ambiente escolar e a problemática socioambiental nas comunidades ribeirinhas no estado do Amazonas, com base na literatura e na observação de campo. Parte-se da seguinte questão: quais os problemas enfrentados e por que promover educação ambiental nas comunidades ribeirinhas amazônicas? Trata-se de um estudo analítico descritivo, que fez uso de entrevistas com registro em áudio e imagens e observação direta com registro em diário de campo. Os sujeitos da pesquisa foram moradores de uma comunidade ribeirinha. A análise dos dados deu-se de forma hermenêutica e a comunicação pautada na metodologia de estudo de caso. Os resultados apontam que a educação ambiental, se pautada na realidade local e promovida dentro das comunidades, torna-se um alicerce para que futuras gerações e, em especial, os próprios moradores se tornem capazes de planejar, desenvolver e superar problemas no ambiente em que vivem.
\end{abstract}

PALAVRAS-CHAVE: Comunidades Ribeirinhas. Qualidade de vida. Educação Ambiental.

Environmental Education: a case study of a riverine community in Amazonas state

\begin{abstract}
This paper aim to discuss the environmental situation of riverine population who lives in the State of Amazonas in Brazil. The discussion
\end{abstract}

\footnotetext{
${ }^{1}$ Mestre em Ciências e Tecnologia para Recursos Amazônicos. Universidade Federal do Amazonas, Itacoatira, Amazonas, Brasil. E-mail: naza.leal27@ hotmail .com.

${ }^{2}$ Doutor em Ensino de Ciências e Matemática. Universidade Federal de Uberlândia, Ituiutaba, Minas Gerais, Brasil. E-mail: olilean@gmail.com.
} 
was grounded in the observation of field and literature. This research started by the following question: what problems are faced and why should be promoted environmental education in these communities? Data are descriptive and collected by interviews recorded by audio and video, also, it was taken note in a notebook of the researcher observation. The subjects of the survey were residents of a riverine community. Data analysis was given in a hermeneutic way and communication was given by a case study. Results show that if the environmental education were guided by local reality and promoted within communities, it becomes a foundation for future generations and, specially, residents become able to plan, develop, and solve problems in the environment in which they live.

KEYWORDS: Riverine communities. Quality of life. Environmental Education.

$$
* * *
$$

\section{Introdução}

O quadro socioambiental que caracteriza as sociedades contemporâneas revela que o impacto dos humanos sobre o meio ambiente tem tido consequências cada vez mais complexas (JACOBI, 2003). Em razão da interação homem-meio ambiente prioritariamente exploratória, registram-se, nas últimas décadas, desastres cada vez mais frequentes.

Esforços individuais são bem-vindos no delineamento dos problemas socioambientais, no entanto, eles não são suficientes porque existe uma demanda coletiva interligada. Isso nos leva a refletir e a procurar meios que envolvam toda a população na solução. Nesse sentido, a escola se apresenta como um possível espaço para reflexão sobre a interação entre homem e meio ambiente. Fernandes e Sampaio (2008) apontam que é importante vincular a perspectiva socioambiental ao estudo dos valores, das crenças, dos diferentes modos de vida, sobretudo de comunidades tradicionais, configurando-se numa proposta paradigmática não só de cunho científico como também de cunho cultural. 
A Amazônia é lugar de natureza privilegiada que ocupa uma diversidade de grupos étnicos e populações tradicionais. No entanto, a fauna e flora tem sido explorada sem consciência crítica e muitas vezes isso ocorre por parte dos próprios moradores que levam a vida fazendo uso da terra, da mata e dos rios. Nesse sentido, a educação escolar e ambiental é de suma importância para os moradores.

A Educação Ambiental pode contribuir para a "compreensão da realidade de uma forma mais complexa por perpassar diferentes campos científicos" (ROSA et al., 2015, p. 215). Educar ambientalmente é formar sujeitos para compreender e agir sobre a complexidade da relação homem e natureza. A problemática socioambiental deve ser enfrentada por uma mudança de paradigma que tenha sustentação em uma racionalidade alternativa aos grandes conflitos da sociedade moderna. Conflitos que são traduzidos pela difícil relação entre desenvolvimento econômico e preservação ambiental (FERNANDES; SAMPAIO, 2008).

Neste artigo, discutiremos a temática educação ambiental, com o foco na problemática das pessoas que vivem no interior do estado do Amazonas nas margens do rio - os caracterizados ribeirinhos amazonenses. No Amazonas os ribeirinhos têm sua origem étnica na mistura de índios, negros e brancos. Vivem em casas de palafitas, do extrativismo da mata, do manejo da terra e da pesca nos rios. As populações ribeirinhas possuem um modo de vida específico, uma relação única e profunda com a natureza e seus ciclos, uma estrutura de produção baseada no trabalho da própria população, com utilização de técnicas prioritariamente baseadas na disponibilidade dos recursos naturais existentes dentro de fronteiras geralmente bem definidas, adequando-se ao que a natureza tem a oferecer, e também manejando quando necessário (MENDONÇA et al., 2007).

Um grande problema atual é a poluição ambiental que tem contaminado os recursos naturais que garantem a sustentabilidade dessa população. O rio é considerado por eles o seu “amigo inseparável”. Dele retirase parte dos alimentos. É na margem fértil do rio que suas plantações de 
subsistência são cultivadas. Ali as crianças se divertem, brincam, correm e nadam, sem conhecer os grandes centros urbanos. A mata também é considerada vital para os ribeirinhos, pois nesse espaço caçam e extraem a madeira para construção de suas casas (a maioria de palafita), para fabricação artesanal de ferramentas e para confecção de canoas. Por outro lado, ironicamente, o rio também é uma estrada pela qual viajam os ribeirinhos: quanto mais próximos dos centros urbanos os rios os conduzem, mais pobres e marginalizados se tornam; quanto mais longe distam deles, menos se conhece sobre sua identidade cultural. Essa situação é controversa e por isso precisa ser compreendida.

Neste estudo nos propusemos a investigar a realidade de uma comunidade e sua escola. Olhamos para o espaço de ensino formal ofertado para as comunidades rurais do estado do Amazonas, o qual inclui os ribeirinhos. O foco da pesquisa voltou-se para entender como o processo de escolarização colabora para a formação de identidades e da cultura. Verificouse que o processo de ensino mesmo sendo limitado desse ponto de vista, têm pequenas iniciativas docentes que buscam torná-los agentes participativos nas soluções de problemas ambientais gerados dentro do seu contexto, estudando sua realidade, trazendo demandas e situações novas.

Na nossa concepção, compreender o contexto ribeirinho pode nos ajudar a conduzir novas pesquisas para reconstruir o sentimento de pertencimento à natureza, assim como ampliar a rede de colaboração participativa dos sujeitos.

\section{Aproximação teórica e o contexto do estudo}

Os resultados da pesquisa de campo relatada é produto de uma dissertação de mestrado do programa de pós-graduação em Ciências e Tecnologia para Recursos Amazônicos da Universidade Federal do Amazonas.

Durante o desenvolvimento do trabalho de conclusão de curso (TCC), disciplina obrigatória do curso de Licenciatura em Ciências: Matemática e 
Física, da Universidade Federal do Amazonas, a primeira autora deste texto adentrou, na posição de pesquisadora, em uma escola estadual ribeirinha, localizada na comunidade Costa da Conceição, zona rural do município de Itacoatiara (AM). Enfatizamos sua posição de pesquisadora pela relevância de informar ao leitor que ela conhecia previamente a realidade dessa escola do ponto de vista de estudante. Sua origem é ribeirinha e fez parte, durante toda a infância e a adolescência, do contexto dessa escola.

O objetivo do estudo no final do curso era conhecer o sistema de ensino ofertado para as escolas estaduais do Amazonas, o programa ensino presencial por mediação tecnológica. A metodologia de pesquisa utilizada na construção do TCC foi um estudo de caso desenvolvido naquela comunidade escolar (NOGUEIRA; SOUZA, 2016).

No decorrer da pesquisa fizemos entrevistas, observação direta com registro em diário de campo sobre os afazeres dos moradores da comunidade no ambiente escolar e análise dos documentos da escola. Após a análise dos assuntos que nos interessavam, percebemos que, além das dificuldades do professor em atuar nesse sistema e da inconformidade da gestora com a estrutura da escola para a adaptação do método, o ensino não era voltado para aquela realidade. $\mathrm{Na}$ nossa concepção isso poderia futuramente causar transformação ou perda da identidade da comunidade e alienação em relação ao conhecimento de seu próprio contexto cultural.

Percebemos também, ao visitar o local na época de enchente (fenômeno que ocorre anualmente nas regiões de floresta amazônica), que muitas famílias naquela comunidade ainda vivem graves problemas socioambientais. E, além disso, ficou evidente a falta de orientações sobre o tratamento que deve ser dado ao lixo, que acaba, muitas vezes, sendo queimado ou lançado ao rio. Como consequência, os detritos são arrastados para igarapés, igapós e lagos, locais onde os ribeirinhos realizam a pescaria para subsistência. Outra questão problemática que conhecemos é que, na época da cheia, as fossas alagam as proximidades das casas, e os ribeirinhos não só tomam banho 
nessas águas, mas também captam-na diretamente dos rios para o próprio consumo, o que, na maioria das vezes, ocorre sem nenhum tratamento.

Essas foram algumas problemáticas locais identificadas na pesquisa e também na realidade vivenciada pela pesquisadora durante sua infância e parte da juventude. O afastamento da comunidade durante o curso de graduação nos fez enxergar a complexidade das relações socioambientais. Ao ingressar no mestrado e iniciar os estudos sobre essa temática, entendemos que seria essencial conhecer a identidade do ribeirinho amazonense, assim como a própria identidade da primeira autora.

Essa pesquisa buscou compreender questões socioambientais e socioculturais dessa comunidade por uma perspectiva teórica hermenêutica.

\section{Procedimento Metodológico}

Para descrever e comunicar os resultados da pesquisa utilizou-se como estratégia o estudo de caso, pelo fato de estarmos olhando para situações particulares de uma comunidade ribeirinha amazônica sem o foco na generalização. Entretanto temos a consciência que cotidianamente outras comunidades ribeirinhas podem vivenciar muitas similaridades com as problemáticas que serão relatadas.

O estudo de caso, segundo Yin (2001, p. 19) trata de questões do tipo "como" e "por quê" e o foco se encontra em fenômenos contemporâneos inseridos em algum contexto da vida real.

Os dados foram alcançados por meio de entrevistas com registro em áudio e imagens, e de observação direta com registro em diário de campo. A interpretação dos dados deu-se por meio da análise hermenêutica, segundo Ghedin (2004, p. 2) "é nela e por ela que se processam os significados".

Fazer pesquisa por essa perspectiva de análise é "trabalhar com a comunicação da vida cotidiana e do senso comum, considerando que o ser humano complementa-se por meio da comunicação, sendo preciso 
compreender seu contexto e sua cultura" (ALENCAR; NASCIMENTO; ALENCAR, 2012, p. 244).

Neste artigo - um recorte da dissertação de mestrado -, a análise hermenêutica nos permitiu entrar em um território chamado pensamento e conhecer o verdadeiro significado daquilo que rodeia as vidas das famílias ribeirinhas da comunidade, buscando a sua percepção e experiência de vida. A pesquisa foi realizada na comunidade Costa da Conceição.

Esse local de estudo foi escolhido pelo fato da primeira autora ter laços culturais e histórico familiar com a comunidade, pois, como já explicitado aqui, antes da sua graduação, a pesquisadora era moradora no local, onde ainda tem laços familiares. Logo, acreditamos que a nossa inserção dentro da comunidade seria bem aceita e facilitaria a participação dos comunitários na pesquisa.

Os sujeitos da pesquisa foram os próprios moradores. Na comunidade havia 34 famílias. Entrevistamos 14 pessoas de 13 famílias diferentes. Os sujeitos foram escolhidos durante visitas e por disponibilidade. Todos eram adultos, entre esses, homens e mulheres de idades entre 18 e 80 anos. As profissões relatadas, embora utilizem a mesma nomenclatura do contexto capitalista contemporâneo (carpinteiro, agricultor, pescador...), diferenciamse por estarem vinculadas ao extrativismo e a pequenas agriculturas onde o comércio e trabalho têm uma função mais social do que capitalista.

$\mathrm{Na}$ escola, dos sete professores apontados nos documentos analisados como atuantes do ensino presencial com mediação tecnológica, apenas os quatro do ensino médio participaram das entrevistas. $\mathrm{O}$ foco desse estudo se inseriu nesta modalidade.

Os dados coletados em processo de diálogo e entrevistas foram transcritos em forma de narrativa, conforme recomendado por Veronese e Guareschi (2006) sobre os modos de transcrição da interpretação na análise hermenêutica.

\section{A comunidade Costa da Conceição, resultados e discussões}


O conceito de comunidade é compreendido como um fenômeno histórico e social, que assume diferentes significados no tempo e no espaço. As reflexões sobre o assunto são repletas de possibilidades de conceitos pautadas em diferentes referências como territorialidade, interesses, organização social e política, valores em comum, sentimento comunitário, entre outros (SILVA; HESPANHOL, 2016).

Para Bauman (2003, p. 7), "comunidade sugere uma coisa boa, é um lugar cálido, um lugar confortável e aconchegante. É como um teto sob o qual nos abrigamos da chuva pesada [...]".

Tönnies (1973) define comunidade como um grupo social caracterizado pelo envolvimento de seus membros com pessoas completas, unidas pelo compartilhamento de sentimentos e emoções e vivendo de forma íntima, privada e exclusiva. Assim concebida, a comunidade estaria representada pela família, pelos grupos de vizinhança, pela aldeia rural etc.

A comunidade aqui apresentada, parte da expressão exposta por Silva e Hespanhol (2016), "comunidade rural" que designa um grupo de pessoas que vive nas áreas rurais e que partilham dos mesmos eventos, tradições e costumes.

A comunidade Nossa senhora da Paz foi fundada no dia 27 do mês de outubro do ano de 1990. Está situada no povoado Costa da Conceição, zona rural do município de Itacoatiara $^{3}$, na margem direita, subindo o rio Amazonas. O acesso à região, tanto do município ao qual pertence a comunidade quanto da capital, Manaus, se dá apenas por meio de embarcações fluviais, de pequeno ou grande porte (NOGUEIRA; SOUZA, 2016).

A criação e o nome a qual recebeu partiu do fato de algumas famílias se sentirem excluídas frente às outras de classes mais elitizadas o que causava

\footnotetext{
${ }^{3} \mathrm{O}$ trajeto a partir da zona central do município é feito de lancha e leva em torno de $3 \mathrm{~h}$. No estado do Amazonas, na maioria dos casos, o transporte é feito via fluvial já que não há estradas que levem a zona rural.
} 
desavenças. A comunidade foi formada inicialmente por 15 famílias e a organização dava-se por um presidente, dois Agentes Comunitários de Saúde, três professoras, grupo de jovens, grupo de mulheres e comissões de homens.

A princípio foi construída uma igreja católica, e em seguida o centro comunitário, ambos feitos de madeira extraída da floresta Amazônica e coberto com palha. A escola funcionava em um prédio de madeira antigo que ficava nas proximidades da comunidade; a classe era multisseriada, mas atendia à demanda de quase todo povoado por ter apenas aquelas três professoras na região.

Segundo as falas dos mais velhos habitantes da comunidade, essa localidade já foi um dia terra de muita fartura (nos anos 90). Os moradores trabalhavam na agricultura, com plantações de mandioca, milho, feijão, melancia, juta, cacau e seringa. No artesanato, trabalhavam com barro, fazendo vasos, alguidar (panela de barro usada para fabricação artesanal de vinhos de frutas regionais), panelas, potes, e manipulavam talas de palmeira jauari (material utilizado para fabricar artesanatos), construíam tipitis (ferramenta artesanal produzida com as talas para espremer e escorrer o vinho), peneiras e peneiros (cesto grande utilizado para carregar produtos agrícolas).

Os Agentes Comunitários de Saúde faziam visitas diárias nas casas e levavam medicamentos e insumos para tratamento de água (na maioria das vezes somente soro e cloro). Sobre a religiosidade, os fiéis participavam do culto dominical na igreja católica.

Com o passar dos anos a comunidade sofreu um retrocesso nas questões de saúde e educação. No ano de 1994 a comunidade foi desligada da prefeitura Municipal de Itacoatiara, do qual fazia parte, e então os Agentes Comunitários de Saúde e a escola foram desativadas. Voltando a ser reconhecida como comunidade social somente no ano de 1996 . No entanto os Agentes Comunitários de Saúde e a escola ficaram definitivamente fora do quadro desta comunidade até atualmente. 
Atualmente a comunidade tem a frente de sua diretoria, um presidente e um vice-presidente, um secretário, um tesoureiro. Compreende trinta e quatro famílias cadastradas e reconhecidas pela prefeitura (possuem carteiras comunitárias rurais) sendo trinta católicas, e quatro protestantes. Três dessas famílias estão ausentes, duas por motivo de estudo e uma por motivo de doença, cinco moram na terra firme, -área da região ribeirinha que não inunda com a enchente- e vinte e sete residem na várzea das margens do Rio Amazonas.

As entrevistas e as memórias em situação de afastamento da comunidade nos fizeram entender que ser ribeirinho, para as famílias da Costa da Conceição, em outros tempos, significava ter orgulho do suor do seu trabalho. No entanto, atualmente, há uma grande espera por benefícios governamentais, o que causa à juventude ociosidade e falta de disposição. Mas, nesse contexto, ao olhar externo, o que seria exatamente ser ribeirinho?

De acordo com a Política Nacional de Desenvolvimento Sustentável dos Povos e Comunidades Tradicionais (BRASIL, 2007), todo aquele que faz parte de grupos culturalmente diferenciados, que possuem formas próprias de organização social, que ocupam e usam territórios e recursos naturais como condição para sua reprodução cultural, social, religiosa, ancestral e econômica, utilizando conhecimentos, inovações e práticas gerados e transmitidos pela tradição, é chamado de morador de comunidade tradicional. Dentre eles estão os ribeirinhos.

A identidade ribeirinha é a revelação de uma camada da sociedade que quase não tem acesso aos bens culturais de tradição erudita (BRITO, 2007). Resultantes da mistura de "etnias e culturas diferentes [...]" e "descendentes da miscigenação de índios, negros e brancos, acompanham os costumes deixados na construção dos seus modos de vida na terra, na mata e nos rios" (OLIVEIRA, 2015, p. 76 e p. 75). Assim sendo, sempre buscaram na natureza recursos para suas sobrevivências. 


\section{A problemática ambiental na comunidade: coleta de dados durante a seca}

Ir à luta e não ter medo do perigo da floresta é o lema que cada ribeirinho carrega, uma vez que os fenômenos de enchentes e erosões fluviais sempre foram seus maiores desafios. Quando citamos enchente, não falamos de uma enxurrada que alaga subitamente um determinado lugar e faz desabar casas. Falamos de algo particular da região amazônica e esperado pelos ribeirinhos: funciona como um dia de maré alta, com a diferença de que, na Amazônia, essa maré não tem ondas nem água salgada, nem dura um dia apenas. É um processo linear, lento e contínuo que muda toda a paisagem.

As erosões fluviais (Figura 1) presentes no Rio Amazonas, conhecidas também pelo termo terra caída (MATOS; NOGUEIRA, 2016), levam parte dos terrenos e deixam em perigo as residências dos ribeirinhos. Seu Carlos, com a casa cheia de netos, se preocupa com a atual situação da comunidade. Para ele, quanto mais longe sua casa estiver da margem do Rio Amazonas, melhor: "outro dia caiu uma casa na comunidade vizinha, eles perderam tudo e graças a Deus não teve morte" (Entrevista, 13 de agosto, 2016).

O morador sabe que o fenômeno é natural "isso são coisas que acontecem mesmo, além de ser várzea a terra, ainda tem muito areia devido essas barragens que fazem aí pra cima" (Lucas, 32 anos. Entrevista, 15 de agosto, 2016).

FIGURA 1 - Erosão Fluvial na comunidade Nossa Senhora da Paz.

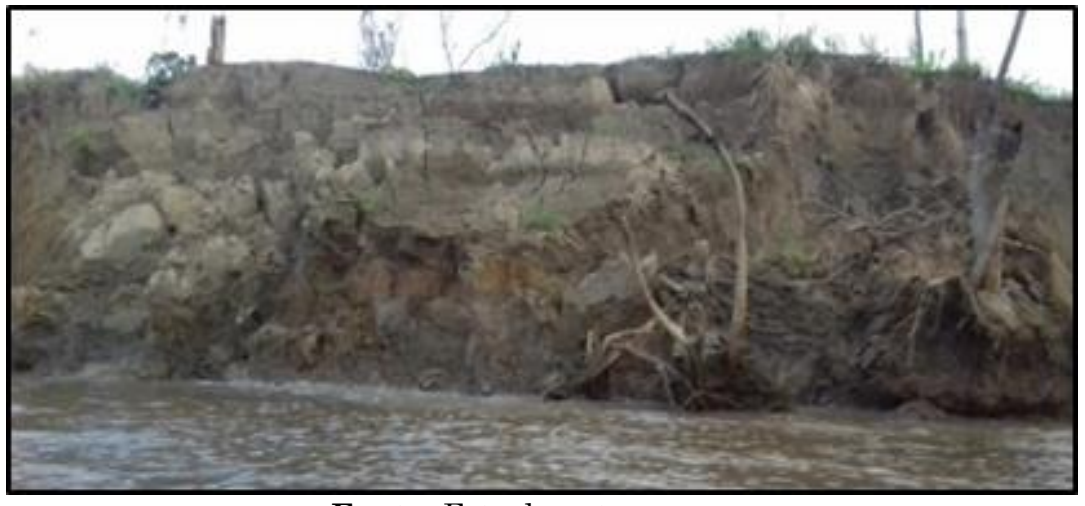

Fonte: Foto da autora 
A enchente ocorre sistematicamente todos os anos, dura meses, enche os rios e faz abrir estradas que foram fechadas na época da seca. Assim, os ribeirinhos não são surpreendidos - pelo contrário, aprenderam a aproveitar os benefícios de cada época do ano. Ao longo da sua vivência nas redondezas do rio, aprenderam a observar a natureza e por isso já sabem quando pode ocorrer uma grande cheia, até mesmo pelo passar de uma andorinha voando próximo das águas.

Por precaução, eles constroem suas casas distantes do solo, alguns metros acima da terra. E, se elas chegarem a ficar encharcadas pela enchente, constrói-se outro piso por cima daquele que está submerso na água. Esse novo piso é chamado de maromba. O rio e a terra são os bens mais preciosos do cidadão ribeirinho do Amazonas (TORRES, 2012).

$\mathrm{Na}$ cultura das comunidades ribeirinhas, a alimentação advém principalmente da pescaria e da agricultura, herdadas dos seus antepassados e mantidas até os dias atuais. A pesca e a agricultura não somente suprem a necessidade alimentícia, mas também geram renda a essa população.

Praticar a pescaria, para um ribeirinho, é responsabilidade que ele carrega ao longo da vida, para o sustento da sua família. No entanto, essa árdua tarefa também lhe proporciona divertir-se na proa de uma canoa enquanto joga conversa fora com outros companheiros da pesca, que dura do início da noite até o amanhecer. Um grande problema é que, muitas vezes, os pescadores são injustiçados no ato da venda do seu pescado para marreteiros, pois lhes falta opção para fazer uma boa venda: não têm para quem vender.

Essa pescaria com a finalidade de alimentação e venda de pequeno porte - no caso, para marreteiros ou feiras-, conforme Cardoso e Freitas (2008, p. 782), é denominada "pesca de subsistência".

Ela é praticada por milhares de pessoas e, por isso, sua produção é difícil de ser quantificada. "É também muito expressiva do ponto de vista cultural, por ser uma atividade comumente praticada por gente de ambos os sexos e de todas as idades e categorias sociais" (SANTOS; SANTOS, 2005, p. 
166). Porém, na comunidade ribeirinha observada, a prática da pescaria é realizada na sua maioria por pessoas do sexo masculino. Excluem-se aqueles que ainda não conseguem pilotar uma canoa, as crianças pequenas e as mulheres que cuidam dos serviços domésticos e dos filhos pequenos.

Outra atividade típica da população ribeirinha é a agricultura, e "sua prática é considerada tradicional de grupos indígenas e não indígenas do Amazonas" (ADAMS; MURRIETA; SANCHES, 2005, p. 3). De acordo com Noda e Noda (2003, p. 61), esse processo produtivo "é direcionado ao atendimento das necessidades da manutenção biológica e social da população rural".

Durante nossas observações diretas na comunidade ribeirinha, percebemos que a concentração da prática da agricultura está na plantação de frutas, como maracujá, graviola e goiaba, e também de alguns frutos específicos da região amazônica como o cupuaçu, a castanha, o tucumã, o açaí, entre outros. Algumas dessas frutas, depois de colhidas, são despolpadas e vendidas. Assim como ocorre na pescaria, as vendas das polpas também são feitas para marreteiros.

É possível ter outras atividades nas comunidades ribeirinhas, além da pescaria e da agricultura. Ser agricultor ou pescador é a profissão natural daquele que decidiu que moraria nessa localidade e sobreviveria da terra, da floresta e do rio. Por exemplo, pode-se trabalhar ali lecionando ou como agente comunitário de saúde; entretanto, para exercer essas profissões, é preciso, antes, optar por deixar seu lar em busca de estudos na zona urbana da cidade.

O agricultor ou pescador ribeirinho convive com profissionais que há muito tempo executam suas atividades. São profissionais que acumularam conhecimentos históricos, transmitidos de geração para geração pela oralidade e pela observação do fazer. Muitos não sabem ler nem escrever, mas conhecem a terra que lhes foi confiada para plantar e cultivar, como se tivessem estudado Agronomia nas mais nobres universidades. Conhecem os peixes e o momento de pescar, como se tivessem cursado e aprendido engenharia pesqueira. 
O que é comum entre a prática de um agricultor ou pescador ribeirinho e os estudos nas universidades é que no campo também existe reprovação. Entretanto, diferentemente das universidades, ali não é o tutor quem define e avalia o nível de aprendizagem. Normalmente, o que ocorre é que a própria natureza se encarrega de impor ao homem limites como resposta às suas ações ou às ações externas à comunidade. Em decorrência dessas ações, a plantação não "dá certo" e a pescaria acaba malsucedida.

É importante que nos voltemos para entender quais são os fatores que causam tais reprovações e o papel da educação ambiental como auxílio para melhoria da qualidade de vida.

Quando iniciamos a coleta de dados, não era época de fartura para a comunidade ribeirinha da Costa da Conceição, e muitas perguntas passavam pela cabeça daqueles moradores: "A terra saiu seca. Nada que se planta nasce. Isso é estranho porque a várzea sempre que sai do fundo volta fértil. Porque a escassez de peixes, se antes nessa época (mês de junho) eles já estavam saindo pelos igarapés?". A fé cristã os fazia questionar se aquele seria o início dos finais dos tempos, quando tudo ficaria mais difícil para todo mundo.

O ribeirinho é, segundo Oliveira (2015), cercado de saberes da tradição, não necessariamente da instrução escolar e do saber científico. Esse sujeito faz sua análise sobre as experiências adquiridas diretamente do contato com a terra e o com rio, de maneira imediata. No entanto, não se pode dizer que os ribeirinhos não são conhecedores de suas intervenções, eles sabem que à longo prazo podem consolidar no desequilíbrio do sistema ambiental, uma vez que toda experiência produz e reproduz conhecimento (SANTOS; MENESES, 2009). Veja o relato da moradora: "Antigamente tudo que plantávamos nascia. De certo tempo pra cá a terra não prestou mais, nós temos medo que um dia não tenhamos mais nem terra ou que o nosso rio fique seco de vez" (Rosário, 45 anos. Entrevista, 26 de setembro, 2016).

Diante das perguntas que tanto os afligiam, em nenhum momento os moradores das margens olhavam ao redor das suas casas e verbalizavam 
sobre o lixo, tanto doméstico como o orgânico, jogado na terra, queimado ou lançado ao rio.

Outro problema observado foi o uso dos agrotóxicos, que com muita frequência eram espalhados na região dos quintais ou pelos caminhos por onde as pessoas andavam, para que o mato não vingasse e as formigas não invadissem as casas. Até mesmo as hortaliças, plantadas em pequenos canteiros ou vasos, eram regadas com esses produtos. Além das pessoas que andam pelos caminhos onde se lançam os agrotóxicos, os animais, como bois, porcos e galinhas (Figura 2) também fazem uso dos lugares e acabam tendo contato direto com esses contaminantes. Os recipientes vazios desses agrotóxicos eram também lançados sem nenhum cuidado no rio.

Os agrotóxicos, além de tornarem o solo fraco para novas plantações, são aplicados, na maioria das vezes, por pessoas sem a menor noção dos riscos que representam à saúde. Elas desconhecem que, se certos cuidados não forem tomados, é possível levar pessoas ao óbito (MUCCI, 2014).

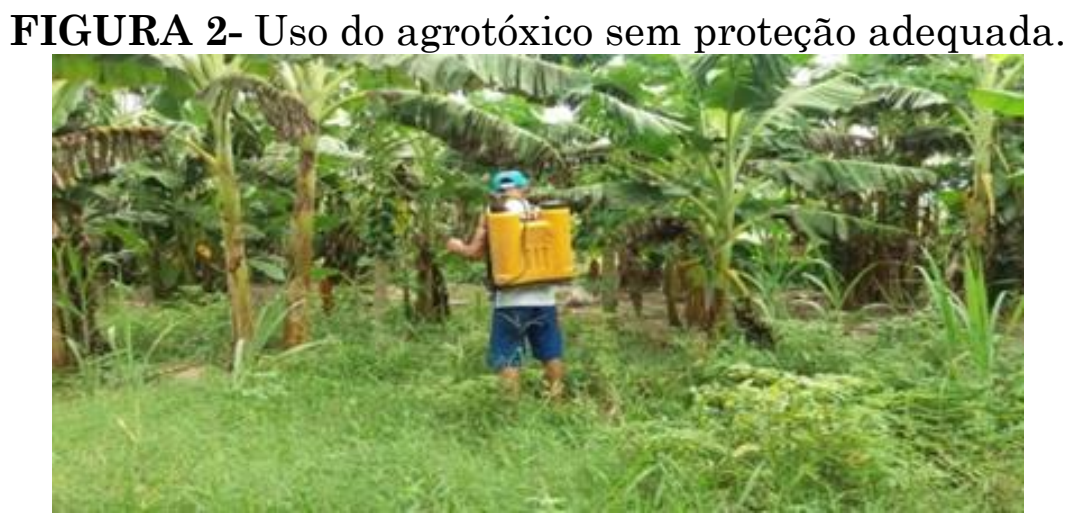

Fonte: Foto da autora.

Um dos relatos apontavam que um dos moradores da comunidade Costa da Conceição estava passando por situação de saúde não muito boa: em seu pé havia aparecido rachaduras que se agravavam a cada mês. Isso ocorria todas as vezes que ele ia ao trabalho sem meia ou sem bota. Para ele, tal rachadura poderia ser resultado de alguma espécie de bruxaria feita por alguém para que ele não trabalhasse mais; ou, como ele próprio dizia: "Só porque eles não têm nada, não querem que tenhamos também e ficam fazendo 
feitiço pra nós". No entanto, na sua fala ele também relatou que o problema apareceu em seu pé no mesmo tempo em que ele começou a adubar com agrotóxico a terra em que fazia suas plantações.

Falar do uso dos agrotóxicos para alguns moradores ribeirinhos dessa comunidade é como se estivessem querendo que confessassem algo errado. Sempre tentam não conversar sobre o assunto. O medo deixa-os desconfiados de que nossa pesquisa iria prejudicar o trabalho destes com a terra. Esquivavam-se para não responder diretamente nossa pergunta, depois de mais uma tentativa, eles explicam que o uso é feito somente para matar os insetos nas plantações e o mato que cresce muito rápido.

Para outros moradores, falar dos agrotóxicos é questão que deveria ser frequentemente discutida.

Deveria ter palestra sobre não usar agrotóxico, ultimamente o uso tem sido muito frequente, a terra já não aguenta mais tanto veneno, e como acham que o produto ajuda no crescimento das plantações e que vão colher mais rápido, começam a colocar pelo meio do roçado, a maioria aqui nessa região só trabalha com isso (Claudio, 43 anos. Entrevista 26 de setembro, 2016).

Nós que trabalhamos com o esterco de boi e paú esperamos um tempo maior pra colhermos os produtos, e para acabar com o mato vamos para o cabo da enxada sem nenhum problema, pelo menos os nossos produtos são saudáveis e não queremos que nossos filhos fiquem sem ter onde morar ou plantar futuramente (Marcelina, 38 anos, entrevista, 3 de agosto, 2016).

O paú é uma espécie de adubo natural utilizado nas plantações, feito pelo morador ribeirinho, de árvores ou troncos de arvores em decomposição, misturado com terra (CASTRO et al., 2007).

Outra prática observada, mais precisamente foram as queimadas. Não aconteciam grandes queimadas, mas eram realizadas com risco. Normalmente aproveita-se o verão para fazê-la e ela cresce e se espalha, chegando a atingir outros terrenos. Presenciamos o desespero de alguns 
ribeirinhos esperando chegar à queimada que havia sido feita em uma comunidade próxima.

Para o ribeirinho amazonense, de maneira imediata, as queimadas representavam riscos, porque poderiam chegar às suas casas. Para o Instituto Brasileiro do Meio Ambiente (IBAMA, 2016), as queimadas também são nocivas porque contribuem para o aquecimento global e para mudanças climáticas, poluem a atmosfera e causam prejuízos econômicos e sociais que aceleram os processos de desertificação, desflorestamento e de perda da biodiversidade.

\section{A problemática ambiental na comunidade: coleta de dados durante a enchente}

$\mathrm{Na}$ segunda fase da coleta de dados, a comunidade se encontrava em período de enchente. O ribeirinho é acostumado a lidar com o fenômeno e não o considera um problema, porém as agravantes contaminações estavam tomando conta dos povos das águas: o lixo dos arredores de suas casas no período da enchente é arrastado pela correnteza até os lagos, os igapós e os igarapés locais, onde os ribeirinhos também realizam atividades de pesca.

$\mathrm{Na}$ cheia, as águas do rio que passam por baixo de suas casas são utilizadas para uso culinário sem nenhum tratamento, assim também ocorre para limpeza local. Já para saciar a sede, a água passa por um processo de limpeza, após ser coletada é armazenada em tanque de plástico as famílias utilizam um material por eles chamado de cloro em pedra. $\mathrm{O}$ que podemos observar na verdade é que a pedra é um reagente colocado para decantar as impurezas da água, separando o barro. Alguns ribeirinhos consideram que a água foi tratada, porque fica límpida e transparente; para outros, o produto utilizado na limpeza causa ardência no estômago.

As fossas são também fontes de contaminação nessas regiões. Construídas nas proximidades de suas casas, na cheia ficam alagadas, as pessoas entram em contato com a água e ficam sujeitas a graves doenças. De acordo com Mucci (2014, p. 18), “a probabilidade da água que contém esses 
dejetos tornar-se um veículo de doenças é bastante grande". Infelizmente para as famílias ribeirinhas é muito difícil evitar o contato com a água. A água é um recurso fundamental para a subsistência de todas as formas de vida no planeta.

Sobre a pescaria, embora os ribeirinhos desta comunidade pratiquem a pesca de subsistência, há aqueles pescadores que aparecem de outras localidades e fazem o uso do arrastão. Muitos peixes juvenis não são aproveitados, são mortos e jogados de volta no rio. "Nós ficamos tristes porque depois eles vão embora e quem vai sofrer somos nós" (Ricardo, 19 anos. Entrevista, 13 de agosto, 2016).

Com respeito a caçada nas matas, houve o relato feito por um morador que demostrou expressão de tristeza no rosto. Ele acredita que uma fase difícil que estão passando, "já teve um tempo que praticamente todos os dias eu trazia uma cutia ou um veado pra comermos, agora é difícil de encontrar até tatú" (Luís, 22 anos. Entrevista, 29 de setembro, 2016). Existe uma nítida singularidade de dependência que o sujeito caboclo tem na sua vida e nas suas dinâmicas, que são regidas pelo tempo, pela natureza, pela história e pelas relações sociais, em diferentes escalas. O fato é que, muitas vezes, a solução da problemática está tão distante dos sujeitos que eles acabam por não ter opção e passam a internalizar com naturalidade suas ações. Os pequenos atos realizados com frequência se acumulam e, com o passar do tempo, começam a mostrar consequências. Poderíamos acreditar, diante dos impactos ambientais gerados pelos moradores ribeirinhos, que essa maneira de tratar a natureza seja parte da cultura ou que não estejam adaptados à geração de lixo não degradável e uso de agrotóxicos.

Não se pode assumir que essa situação seja uma problemática apenas cultural. O problema deve ser encarado como falta de formação crítica. Muitas vezes à problemática tem como causa a adaptação dos sujeitos às mudanças que lhes são impostas por outras culturas tradicionais. Os problemas socioambientais e culturais se intensificam constantemente. É preciso formar cidadãos para estudar e solucionar os problemas socioambientais na 
localidade em que eles se encontram inseridos (PHILIPPI JR, PELICIONI; 2014), pois, além de o cidadão se tornar agente participativo, irá colaborar para a melhoria e a qualidade de vida do seu grupo. Por exemplo, ajudando a produzir estudos para exigir dos fabricantes de defensivos, e do poder público municipal e agentes comerciais e de prestação de serviços que ofereçam serviços que respeitem a cidadania destes povos: coleta de embalagens, coleta de lixo/resíduos com periodicidade suficiente, análise da qualidade da água frequente, políticas públicas que prezem pela justiça social e ambiental, campanhas informativas que não sejam apenas de cunho comportamental e reducionista, mas com sensibilidade/responsabilidade histórica e geográfica, etc.

Por meio da construção de conhecimentos a partir de estudos sobre o seu próprio contexto, a educação ambiental pode se apresentar como uma proposta de luta social buscando processos políticos democráticos que fortaleçam a cidadania, preparando os sujeitos para uma relação de cuidado e preocupação com o ambiente e com os problemas que afetam suas rotinas diárias (LUCCA; BRUM, 2013).

Refletir sobre a educação a mbiental ao mesmo tempo em que refletimos também sobre a educação escolar favorece uma compreensão maior sobre as demandas do ambiente em que se vive, uma vez que ambas estão interligadas. Para uma criança da zona urbana que vê o caminhão de lixo passar na porta da sua casa, é mais fácil dizer que não se pode simplesmente jogar lixo nos quintais. Nesse mesmo lugar, onde o alimento chega com fartura no supermercado, também não é preciso fazer uso de agrotóxicos. Porém, nesse contexto, é mais fácil internalizar que esses produtos podem causar danos a sua saúde e ao meio ambiente. A criança urbana crescerá embasada nessas afirmações. Por isso, autores, como, D’Ambrosio (2002), Freire (1987) e Brandão (2002), salientam que os saberes tradicionais, as crenças, a cultura das populações, o meio ambiente, são questões que precisam ser consideradas nas discussões das propostas pedagógicas nas escolas. 
Os ribeirinhos, no entanto, aprendem cedo a conviver com as problemáticas da floresta úmida e tropical, com a falta de infraestrutura, com o solo pobre em nutrientes. As palavras usadas nas comunidades urbanas certamente não terão ali o mesmo efeito; e é provável que não sejam nem levadas em consideração. Esse pode ser um importante tema gerador de pesquisa na educação ambiental.

Os filhos dos ribeirinhos da comunidade observada frequentam aulas mediadas tecnologicamente por satélites, vinculadas à central localizada em Manaus, capital do estado do Amazonas. O ensino presencial com mediação tecnológica é transmitido para várias comunidades rurais do estado. Logo nos questionamos: Que cultura está sendo vivenciada? Que identidade está sendo construída? E para qual sociedade?

Um dos professores entrevistados relata:

"Não dá para esperar que o ensino tecnológico vá abordar questões que envolva o cotidiano dos nossos alunos, o público que frequenta é imenso, em várias partes do estado. Os nossos alunos são a maioria agricultores, pescadores ou donos de pequenos comércios, quanto as outras comunidades eu não sei como são.” (Professor 3. Entrevista, fevereiro, 2017).

Os relatos mostram que professores tutores estão atentos a essa questão:

"Todos nós sabemos que o dia a dia do aluno deve ser inserido de alguma forma nos conteúdos escolares. Na minha sala eu faço isso, sou formada em geografia e exploro bastante essa questão da realidade. Falo sobre as questões climáticas, uso nosso ambiente como exemplo" (Professor 2. Entrevista, fevereiro, 2017).

"Eu viso muito as questões das doenças. Na nossa região temos muito lixo nos arredores das casas, e o acúmulo de água parada nos recipientes abandonados. Viso bastante também a questão social, 
como drogas e gravidez na adolescência, esses dois itens são atualmente a maior realidade aqui na nossa escola, e na nossa comunidade, principalmente as drogas. Discuto bastante essas questões nas minhas aulas, e também na hora da transmissão.” (Professor 1, Ensino Médio. Entrevista, fevereiro, 2017).

Fazer a ligação entre o contexto da comunidade e os assuntos tratados na escola se torna fundamental para os moradores ribeirinhos. Dessa maneira, o ensino e a aprendizagem passariam a ser coletivos, "ninguém educa ninguém, ninguém educa a si mesmo, os homens se educam entre si mediatizados pelo mundo" (FREIRE, 1987, p. 39). Preparar cidadãos para atuarem na sua realidade na comunidade ribeirinha envolve também a ideia de que muitos deles vivem no isolamento geográfico e em situação de exclusão social. Sendo incluídos nas políticas públicas gerais governamentais sem que as especificidades de seu modo de vida sejam consideradas (SILVA et al., 2010), isso reflete nos grandes problemas de economia, de educação e de saúde.

É preciso estudar os modos de vidas e a relação cultural com a natureza, para então, formá-los para que se tomem parte na solução dos seus problemas. Essa seria uma contribuição da escola para a comunidade. Dessa forma, as respostas para as questões não precisariam ser buscadas fora da sua localidade. Cabe à escola formar indivíduos que reflexivos, que olhem e compreendam criticamente o seu contexto; que se preocupem com o destino coletivo, com a equidade e justiça social; que saibam se posicionar diante dos desafios do mundo (OLIVA, 2000).

A cultura escolar deveria preocupar-se mais com um ensino que não mudasse a cultura dos ribeirinhos, mas os preparasse para viver na sua cultura, construindo sua identidade com o olhar voltado para sua localidade. Construir uma identidade não depende exclusivamente de seu querer, mas exige se inserir em um espaço discursivo onde identidades são produzidas e 
processadas. Exige estudar a materialidade, politicidade e geograficidade da vida cotidiana - e não apenas a dimensão simbólica-discursiva.

\section{Conclusão}

As dificuldades enfrentadas nas comunidades ribeirinhas nas questões socioambientais passam despercebidas na visão governamental (SILVA et al., 2010). Quanto mais o tempo passa, mais consequências podem vir à tona. Pensar em soluções que não envolvam as pessoas desse ambiente talvez tenha sido a coisa certa a fazer.

O trabalho sustentado por meio da educação ambiental, de acordo com Rosa et al., (2015), serve de estratégia de reflexão para a sociedade ou para o grupo pelo qual é desenvolvido, a fim de novamente estabelecer valores e criar uma nova identidade coletiva, inserindo os sujeitos como formadores de opinião e não apenas como cumpridor de ordens ou regras.

O ribeirinho precisa de professores preparados para atuar, no ambiente e na comunidade em que se insere a escola, diante dos problemas que por ali surgirem. E as respostas e as soluções devem ser encontradas dentro desse mesmo ambiente. Valorizar a cultura ribeirinha é, acima de tudo, não permitir que "sobre o medo e angústia de um saber pouco valorizado em relação à cultura urbana" (LIMA; ANDRADE, 2010, p. 58). É saber se encontrar dentro do seu ambiente, se questionar sobre onde está e o que pode ou deve fazer ali.

A educação ambiental deveria ser considerada com mais atenção nas comunidades ribeirinhas do Amazonas. Os motivos para promovê-la estão crescendo com mais intensidade nessas localidades. Cabe tanto à escola dar mais importância às questões reais do ambiente e da comunidade em que está implantada, quanto à comunidade extraescolar também participar ativamente dessas questões.

Este artigo pretendeu contribuir com as pesquisas que estudam educação ambiental em comunidades ribeirinhas na medida em que 
apresenta o quadro socioambiental de uma localidade no interior do estado do Amazonas. No entanto, a pesquisa não finda por aqui, abrem-se novos leques de questões que ainda precisam ser investigadas.

\section{Referências}

ADAMS, Cristina; MURRIETA, Rui Sérgio; SANCHES, Rosely. Agricultura e alimentação em populações ribeirinhas das várzeas do Amazonas: novas perspectivas. Ambiente \& Sociedade, São Paulo, v. 8, n. 1, p. 65-86, 2005.

ALENCAR, Tatiane; NASCIMENTO, Maria; ALENCAR, Bruno. Hermenêutica dialética: uma experiência enquanto método de análise na pesquisa sobre o acesso do usuário à assistência farmacêutica. Revista Brasileira em Promoção da Saúde, Fortaleza, v. 25, n. 2, p. 243-250, 2012.

BAUMAN, Zygmunt. Comunidade: a busca por segurança no mundo atual. Rio de Janeiro: Zahar, 2003.

BRANDÃO, Carlos. O que é educação. São Paulo: Brasiliense. 2002, 117 p.

BRASIL. Decreto ${ }^{\circ}$ 6.040, de 7 de fevereiro de 2007. Institui a Política Nacional de Desenvolvimento Sustentável dos Povos e Comunidades Tradicionais. Diário Oficial da República Federativa do Brasil, Brasília, DF, 7 de fevereiro de 2007. Disponível em: http://www.planalto.gov.br/ccivil_03/_ato2007-2010/2007/decreto/d6040.htm. Acesso em: 15 ago. 2015.

BRITO, Maria. Educação matemática, cultura amazônica e práticas pedagógicas: a margem de um rio. Dissertação (Mestrado) - Núcleo Pedagógico de Apoio ao Desenvolvimento Científico) - Universidade Federal do Pará, Belém, 2007.

CARDOSO, Renato; FREITAS, Carlos. A pesca de pequena escala no rio Madeira pelos desembarques ocorridos em Manicoré (estado do Amazonas), Brasil. Acta Amazônica, Manaus, v. 38, n. 4, p. 781-788, 2008.

CASTRO, Albejamere et al. A agricultura familiar: principal fonte de desenvolvimento socioeconômico e cultural das comunidades da área focal do Projeto Piatam. In: FRAXE, Therezinha, PEREIRA; Henrique; WITKOSKI, Antônio (Orgs.) Comunidades ribeirinhas amazônicas: modos de vida e uso dos recursos naturais. Manaus: EDUA, 2007, v. 2, p. 55-88.

D’AMBROSIO, Ubiratan. Etnomatemática e educação. Reflexão e Ação, Santa Cruz do Sul, v. 10, n. 1, p. 7-19, 2002.

FERNANDES, Valdir; SAMPAIO, Carlos. Problemática ambiental ou problemática socioambiental? A natureza da relação sociedade / meio ambiente. Desenvolvimento e Meio Ambiente, Curitiba, n. 18, p. 87-94, jul./dez. 2008.

FREIRE, Paulo. Pedagogia do oprimido. 17. ed. Rio de Janeiro: Paz e Terra, 1987. 
GHEDIN, Evandro. Hermenêutica e pesquisa em educação: caminhos da investigação interpretativa. In: SEMINÁRIO INTERNACIONAL DE PESQUISA E ESTUDOS QUALITATIVOS, 2., 2004, Bauru. Anais... Disponível em: https://arquivo.sepq.org.br/II-SIPEQ/Anais/pdf/gt1/10.pdf. Acesso em: 09 maio, 2019 .

INSTITUTO BRASILEIRO DO MEIO AMBIENTE. Incêndios florestais. Disponível em: <http://www.ibama.gov.br/prevfogo/incendios-florestais>. Acesso em: 18 mar. 2016.

JACOBI, Pedro. Educação ambiental, cidadania e sustentabilidade. Cadernos de Pesquisa, São Luís, v. 118, n. 3, p. 189-205, 2003.

LIMA, Maria; ANDRADE, Erika. Os ribeirinhos e sua relação com os saberes. Revista Educação em Questão, Natal, v. 38, n. 24, p. 58-87, maio/ago. 2010.

LUCCA, Emerson; BRUM, Argemiro. Educação ambiental: como implantá-la no meio rural? Revista de Administração IMED, Passo Fundo, v. 3, n. 1, p. 33-42, 2013.

MATOS, Jônatas; NOGUEIRA, Amélia. As terras-caídas no careiro de várzea e as implicações para os moradores da comunidade Miracauera no Paraná do Careiro (Careiro da Várzea- AM). Revista Geonorte, Manaus, v. 5, n. 20, p. 128-134, Out. 2014.

MENDONÇA, Maria et al. Etnobotânica e saber tradicional. In: FRAXE, Therezinha, PEREIRA; Henrique; WITKOSKI, Antônio (Orgs.) Comunidades ribeirinhas amazônicas: modos de vida e uso dos recursos naturais. Manaus: EDUA, 2007, v. 2, p.

MUCCI, José. Introdução às ciências ambientais. In: PHILIPPI JR, Arlindo; PELICIONI, Maria Cecília Focei. (Org.). Educação ambiental e sustentabilidade. 2. ed. Tamboré: Manole Ltda., 2014. v. 1, p. 16-36.

NODA, Hiroshi; NODA, Sandra. Agricultura familiar tradicional e conservação da sócio biodiversidade amazônica. Interações, Campo Grande, v. 4, n. 6, p. 55-66, 2013.

NOGUEIRA, Maria; SOUZA, Leandro. O ensino presencial por mediação tecnológica e o aprendizado da matemática no interior do estado do Amazonas. In: ENCONTRO NACIONAL DE EDUCAÇÃO MATEMÁTICA, 12., 2016, São Paulo. Anais... Disponível em: < http://sbem.bruc.com.br/xiienem/pdf/6200_2662_ID.pdf>. Acesso em: 09 ago. 2016.

OLIVA, Jaime. A educação ambiental na escola. In: MINISTÉRIO DA EDUCAÇÃO. Secretaria de Educação a Distância. Textos da Série Educação Ambiental do Programa Salto para o Futuro. Brasília, jun. 2000.

OLIVEIRA, José. Os ribeirinhos da Amazônia: das práticas em curso à educação escolar. Revista de Ciências da Educação, São Paulo, v. 1, n. 32, p. 73-95, 2015. 
PHILIPPI JR, Arlindo; PELICIONI, Maria. Bases políticas, conceituais, filosóficas e ideológicas da educação ambiental. In: PHILIPPI JR, Arlindo; PELICIONI, Maria Cecília Focei. (Org.). Educação ambiental e sustentabilidade. 2. ed. Tamboré: Manole Ltda., 2014. v. 1, p. 3-12.

ROSA, Teresa et al. A educação ambiental como estratégia para a redução de riscos socioambientais. Ambiente \& sociedade, São Paulo, 2015, v.18, n.3, p. 211-230.

SANTOS, Boaventura; MENESES, Maria. Epistemologias do sul. Coimbra: Almedina, 2009. $532 \mathrm{p}$.

SANTOS, Geraldo; SANTOS, Ana. Sustentabilidade da pesca na Amazônia. Estudos avançados, São Paulo, v. 19, n. 54, p. 165-182, 2005.

SILVA, Juniele; HESPANHOL, Rosangela. Discussão sobre comunidade e características das comunidades rurais no município de Catalão (GO). Sociedade \& Natureza, Uberlândia, v. 28, n. 3, 361-374, set/dez, 2016.

SILVA, Simone et al. Rotinas familiares de ribeirinhos amazônicos: uma possibilidade de investigação. Psicologia: teoria e pesquisa, Brasília, v. 26, n. 2, p. 341-350, 2010.

TÖNNIES, Ferdinand. Comunidade e sociedade como entidades típico-ideais. In. FERNANDES, Florestan (Org.) Comunidade e sociedade. 1 ed. São Paulo: Nacional, 1973, p. 97- 285.

TORRES, Iraildes. O Ethos das mulheres da floresta. 22. ed. Manaus: Valer, 2012. VERONESE, Marília; GUARESCHI, Pedrinho. Hermenêutica de profundidade na pesquisa social. Ciências Sociais Unisinos, São Leopoldo, v. 42, n. 2, p. 85-93, 2006.

YIN, Robert. Estudo de caso: planejamento e métodos. 2. ed. Porto Alegre: Bookman, 2001. ABREU, M. C. T. Azevedo de. O professor universitário em aula: prática e princípios teóricos. São Paulo: Cortez, 1980. 